\title{
Critical stresses for cancer cell detachment in microchannels
}

\section{(Cell detachment in microchannels)}

\author{
Cécile Couzon · Alain Duperray · Claude Verdier
}

Received: date / Accepted: date

\begin{abstract}
We present experiments involving cancer cells adhering in microchannels, subjected to increasing shear stresses $(0.1 \mathrm{~Pa}$ to $30 \mathrm{~Pa})$. Morphological studies are carried out at different shear stresses. Cells exhibit spreading patterns similar to the ones observed in static conditions, as long as the shear stress is not too high. At critical wall shear stresses (around $2-5 \mathrm{~Pa}$ ), cells decrease their cell-substrate contact area until detachment at the larger stresses. Critical shear stresses are found to be lower for higher confinements (i.e. smaller cell height to channel height ratio). Fluorescent techniques are also used to localize focal adhesions (typically $1 \mu \mathrm{m}^{2}$ in size) under various shearing conditions, showing that cells increase the number of focal contacts in the region facing the flow. To analyze such data, we propose a model to determine the critical stress, resulting from the competition between hydrodynamic forces and the adhesive cell resistance. With this model typical adhesive stresses exerted at each focal contact can be determined and are in agreement with previous works.
\end{abstract}

Keywords Microfluidics · Cancer cells $\cdot$ Critical stress $\cdot$ Focal adhesions

PACS PACS 87.17.Rt · PACS 87.64.-t · 07.10.Cm

Cécile Couzon

Laboratoire de Spectrométrie Physique, CNRS-Université Grenoble I (UMR 5588)

140 avenue de la physique, BP 87, 38402 Saint-Martin d'Hères cedex, France

Alain Duperray

(a) INSERM, U823, Grenoble, France

(b) Université Joseph Fourier-Grenoble I, Faculté de Médecine

Institut d'oncologie/développement Albert Bonniot et Institut Français du Sang, UMR-S823, Grenoble, France

Claude Verdier

Laboratoire de Spectrométrie Physique, CNRS-Université Grenoble I (UMR 5588)

140 avenue de la physique, BP 87, 38402 Saint-Martin d'Hères cedex, France

Tel.: +33476635980

Fax: +33476635495

E-mail: verdier@ujf-grenoble.fr 


\section{Introduction}

The response of cells to mechanical stresses is a key factor in many biological processes like cell division, embryogenesis, cell migration, diapedesis, etc. Typical examples concern the reaction to shear stresses exerted as cells travel through the blood, or when they adhere to the vascular wall, but also within tissues, since cells are submitted to various forces due to the environment. As a first sketch, cells exert a different response as a function of substrate stiffness [18] and develop stronger forces when the substrate is more rigid [32]. They also develop larger forces as they spread $[15,43]$ or as the ligand concentration increases. Cells might also change their orientation as a function of environmental anisotropy, leading to cell polarization as shown in recent experiments on specific micropatterned surfaces [49]. But their orientation might also depend on the type of forces to which they are subjected to, like static, quasistatic or periodic stresses [15]. Reaction to mechanical stresses involves mechanotransduction, or how forces are converted into biochemical and functional responses. This transduction of external forces into an adapted cell behavior requires first sensing of external forces, then transmission of forces from outside the cell through cell-matrix and cell-cell contacts, leading to the initiation of intracellular signalling cascades that alter cellular behaviors. Although some aspects of this machinery remain unclear, it is known that a dynamic feedback takes place implying external mechanical force, signaling, internal force, which lead to the reorganization of the cytoskeleton, as well as the formation or disruption of focal adhesions [9,26,39]. For example focal contacts can act as mechanosensors and enable growth of further adhesion sites [44] in the case of adhering fibroblasts. An additional effect is the actin reorganization of a cell under flow, as shown for example with Dyctiostelium discoideum [13]. Flow reversal leads to a change in cell polarity, corresponding to relocalization of an actin-rich region opposite of the flow. In other words, cells are able to modify their local rheological properties [51] in order to achieve a particular response.

Many experiments have been achieved in the past for studying cell behaviour under flow, as a particular way to apply mechanical stresses to adhering cells. This aspect is particularly important when trying to model leukocyte/cancer cell interactions with the endothelium [28,

52]. First interaction with the endothelium is followed by cell activation and formation of 
weak bonds leading to cell rolling [30], followed by mechanotransduction and the formation of stronger bonds, allowing cells to adhere, spread and eventually transmigrate across the endothelial monolayer. During this process, it is important to determine what forces are necessary to detach such bonds (i.e. when tumor cells adhere to the endothelium), and to determine the force and/or the number of bonds needed for the cell to resist against the flow [11]. Another important application is the transport of cells in microchannels which is now becoming very promising, especially with the recent advances of microfluidics which could allow the sorting of normal cells vs. cancer cells. Experiments on the influence of a controlled flow rate (or shear stress) on adhering cells have been performed in parallel plate flow chambers $[41,6,10,14]$ or radial flow experiments [16], or with micropipettes [36,12, 4]. Such devices allow to control the applied shear stresses, usually chosen in the range [0.1$2 \mathrm{~Pa}$ as in physiological conditions. Particular attention has been given to endothelial cells under flow conditions. Thoumine et al. [50] showed that endothelial cells become elongated in the flow direction in an almost regular manner, and that the underlying actin cytoskeleton also aligns in the same direction. Chachisvilis et al. [7] finally demonstrated the role of G-protein coupled receptors, which act as mechanosensors, as was shown before for other proteins such as integrins and cadherins [46].

To further investigate the response of a cell exposed to a flow field, it is necessary to find out theoretically which forces and torques are applied to the adhering cell, depending on flow geometry. Pozrikidis [42] determined numerically forces and torques exerted by a 3D shear flow on an adhering cell, assuming the cell to be a spherical cap or an ellipsoid, but the study was limited to an infinite flow domain. Gaver and Kute [22] studied analytically and numerically the effect of flow on a 2D adherent cell in a microchannel and generalized this idea to the 3D-case, coming up with simple formulas depending on confinement. The confinement $R / h$, i.e. the ratio between cell height $(R)$ and channel height $(h)$ determines how the cell obstructs the microchannel, $R / h \rightarrow 1$ meaning that the cell blocks the channel whereas $R / h \rightarrow 0$ means a high channel or a small cell. Once the flow field is known, models of adhesion and detachment can then allow to determine dissociation rate constants [24], since cell detachment is controlled by the ability of cells to form bonds between its receptors 
and the corresponding ligands on the surface. Still it is not known what are the precise mechanisms by which cells spread and adhere under flow.

Therefore the purpose of the present study is to focus on experimental results where cells adhering to the walls of a microchannel are subjected to an increasing shear flow until detachment. This implies modifications of the cells morphology, in relation with their adhesion properties and the flow characteristics. This is not only relevant for microfluidics, but is also a true situation encountered in post capillary venules $(5-200 \mu \mathrm{m}$ in size $)$ where circulating cells interact with the vessel walls and adhere. Recent developments have enabled the study of cell migration $[45,8,27]$ and adhesion strength $[33,54,23,29]$ in confined geometries. Most of these studies consist in end-point assays, i.e. measuring the total distance the cells migrate or counting the fraction of remaining adherent cells at the end of the experiment. The present motivation is here to analyze carefully the cell behaviour, in particular what exact stresses or forces are necessary to achieve cell detachment, and how this can be related to cell adhesion. We will focus on a particular type of cancer cells (T24, an epithelial bladder type) and investigate the action of a flow field while comparing it with the adhesion sites formed below the cell. This study can serve as an interesting tool for estimating the typical force per adhesion site by which this type of cell adheres to a given substrate. This can be obtained thanks to fluorescence microscopy observations of focal adhesions, enabling the count of such adhesion sites and their size.

The paper is organized as follows. In the first part, we describe materials and methods, in particular cells, microchannels build-up, fluorescence microscopy, and the working equations governing flow parameters. Then results are collected to describe cell spreading and detachment, in order to propose a new method for determining the critical stress for cell retraction. In the final part, the effect of confinement on the critical shear stress is discussed, then we use a model based on previous work [22] to interpret our data and come up with the missing parameters in the adhesion model. This enables us to determine typical forces involved at each focal adhesion site. Such results obtained for this type of cells are then compared with previous studies. 
Materials and methods

\section{Cell culture}

T24 is a human epithelial bladder cancer cell line (ATCC No HBT-4). In our experiments, T24 cells were cultured in $25 \mathrm{~cm}^{2}$ tissue culture flasks (T25) at $37^{\circ} \mathrm{C}$, in a humidified atmosphere with $5 \% \mathrm{CO}_{2}$. The cells were incubated in RPMI supplemented with $100 \mathrm{U} / \mathrm{mL}$ penicillin and $100 \mu \mathrm{g} / \mathrm{mL}$ streptomycin and $10 \%$ fetal calf serum. Cells were grown to near confluence in the culture flasks and then suspended with $0.05 \%$ trypsin-EDTA solution. The concentration of suspended cells was determined using a Neubauer cell, before being introduced into the microchannels.

\section{Long term experiments under static conditions}

T24 cells in culture medium were placed on a glass slide recovered by a thin layer of PDMS $(<0.5 \mathrm{~mm})$. Culture medium height was roughly $1.5 \mathrm{~mm}$. Cells were left to sediment and spread in static conditions. Phase-contrast images were taken every five minutes. The substrate and the coating were the same as the ones used in microchannels, consequently these experiments under static conditions can be used as a control for the experiments under flow conditions.

\section{Design of microfluidic devices}

The microfluidic devices were made using the PDMS rapid photolithographic technique according to previous works [20]. The photolithography masks bearing the channel design were printed on high resolution films. The negative masters were then created from a photopatternable epoxy (SU-8, Gersteltec) spin-coated onto silicon wafers, and exposed to UV light through the film negative of the desired channel size. The silicon was then etched with inverse structures of the microfluidic channels : typically $1 \mathrm{~mm}$ width (w) and $50-300 \mu \mathrm{m}$ height (h, measured by Scanning Electron Microscopy - SEM - afterwards). The PDMS elastomer devices were molded from the masters using two-part Sylgard silicon elastomer (a mixture of 1:10 silicon elastomer and curing agent degased and poured against the silicon master). Once cured, each PDMS device was punched with inlet/outlet holes, treated with 
air plasma $\left(2.10^{-4}\right.$ bar at $6.8 \mathrm{~W}$ coil power for 40 seconds), bonded to the glass slide by putting both treated surfaces in contact to each other immediately after, and connected to tubes which were sealed with glue (Araldite). In order to prevent bubbles from entering the channel, a bubble trap was also included into the microfluidic device as shown in Fig. 1.

\section{Channel coating and cell loading for shearing experiments}

Prior to each experiment, the microchannel walls were functionalized with a fibronectin solution $(20 \mu \mathrm{g} / \mathrm{mL})$ for one hour at a typical flow rate of $0.8 \mathrm{~mL} / \mathrm{h}$ in order to allow fibronectin adsorption onto the treated PDMS surfaces. The bubble trap was then filled with culture medium. Finally the channel was rinsed for 15 minutes with culture medium.

Cells (diameter $\sim 15 \mu \mathrm{m}$ ) in suspension at a concentration adapted to the channel size (in the range $1-5.010^{6}$ cells $/ m L$, or an equivalent volume concentration of $0.05-0.28 \%$ ) were pumped into a microfluidic device at a small flow rate $Q$ corresponding to a small wall shear stress (in the connection tube) less than $0.1 P a$. Typically $Q=10 \mathrm{~mL} / \mathrm{h}$ in a cylinder of radius $r=0.4 \mathrm{~mm}, \eta \sim 10^{-3} \mathrm{~Pa} . \mathrm{s}$ at $37^{\circ} \mathrm{C}$, which leads to a wall shear stress in the connection tube $\sigma=4 \eta Q / \pi r^{3}=0.055 P a$. Once located in the channel, cells were left at rest for 15 minutes to allow attachment to the channel wall.

\section{Experiments under controlled flow conditions}

Shearing experiments were performed to investigate cells responses and their ability to resist the flow. In particular, measurement of the cell area over a range of shear stresses is important to determine the effect of flow on adherent cells. During measurements, a continuous flow was applied and a region of interest (ROI) in the center of the channel was investigated at fixed time intervals (15 seconds). The flow rate was changed regularly every 5 minutes, starting at low flow rates and then increasing, inducing higher shear stresses progressively. In all cases, the Reynolds number given by $R e=\rho V D_{h} / \eta$ was less than 130 (where $D_{h}=w h / 2(w+h)$ is the hydraulic diameter and $V$ the mean fluid velocity), indicating that the flow was laminar. Images were taken at the center of the channel, away from the side walls, to ensure the full development of the velocity profile. Individual cell morphologies (area, angle, aspect ratio, etc.) were recorded in real time using phase contrast microscopy. A global view of the experimental set-up can be seen in Fig. 1. 


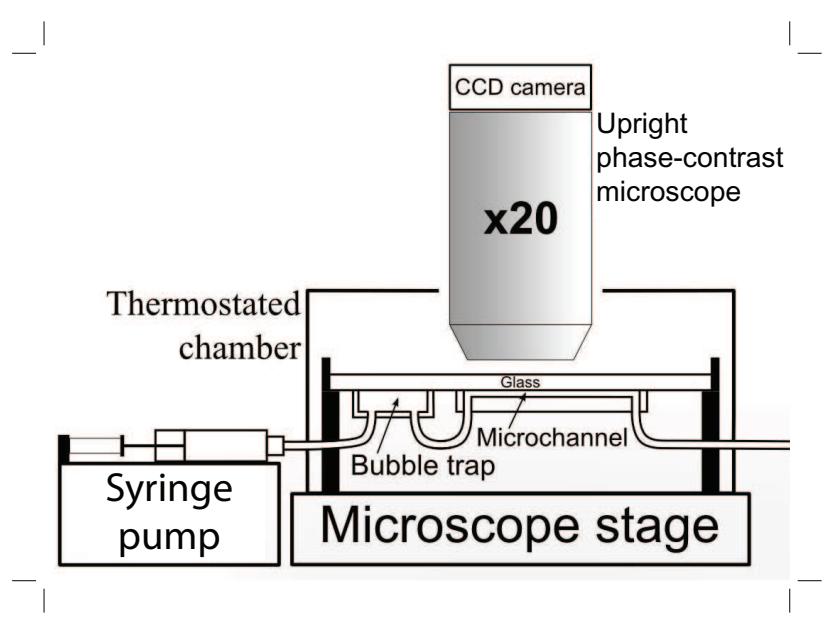

Fig. 1 Full view of the experimental set-up. The microfluidic device is placed in a thermostated chamber at $37^{\circ} \mathrm{C}$ under the $\mathrm{x} 20$ objective of an up-right phase contrast microscope. Fluid flow is controlled by a syringepump. Before reaching the microchannel, the fluid first passes through the bubble trap (completely filled with medium before the experiment), where bubbles remain trapped.

\section{Determination of the Wall Shear Stress (no cell)}

To determine the Wall Shear Stress (WSS) with no cell in the channel, the stress vector on an oriented facet (normal unit vector $\vec{n}$ ) is introduced: $\vec{t}(\vec{n})=\Sigma \cdot \vec{n} . \Sigma$ is the shear stress tensor, given by $\Sigma=-p \mathbf{I}+2 \eta \mathbf{D}$ for a Newtonian incompressible fluid, $\eta$ is the fluid viscosity, $\mathbf{D}$ is the symmetrical part of the fluid velocity gradient tensor and $p$ is the pressure. $\vec{v}$ is the fluid velocity and only has a $z$-component depending on $x$ and $y$, in the coordinate system shown in Fig. 2 because of the translational invariance. Note that the cell is shown in order for this Figure to be used later on, although the channel is empty in this part.

Consequently the shear stress depends on the velocity field $\vec{v}$ which is described by the steady Navier-Stokes equations. In the case of an incompressible Newtonian fluid, the fluid velocity $\vec{v}$ and the pressure $p$ are solutions of the system:

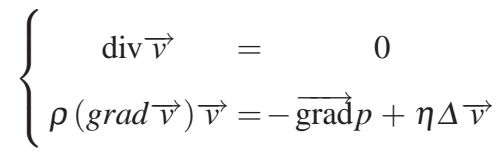

together with boundary conditions $\vec{v}\left(-\frac{w}{2}, y, z\right)=\vec{v}\left(\frac{w}{2}, y, z\right)=\vec{v}(x, 0, z)=\vec{v}(x, h, z)=\overrightarrow{0}$, where $\rho$ is the fluid density. 


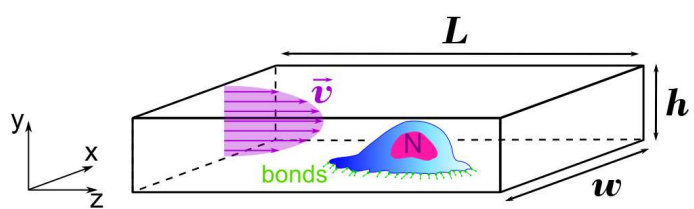

Fig. 2 Schematic view of the microchannel (height $h$, width $w$ and length $L$ ) used in the experiments, with a cell (nucleus $\mathrm{N}$ ) adhering to the bottom wall. The system of coordinates chosen to describe the flow field $(-w / 2<x<w / 2,0<y<h$ and $0<z<L)$ and the velocity profile in a cell free channel are represented on the left.

The previous system (1) can be solved for the only component $v_{z}(x, y)$ using Fourier series decomposition [55]. Assuming a constant pressure gradient $\Delta p / L$ (where $\Delta p$ is the pressure drop over the length of the channel $L$ ) corresponding to the channel sketched in Fig. 2, the solution reads :

$$
v_{z}(x, y)=\frac{\Delta p}{\eta L} \frac{4 h^{2}}{\pi^{3}} \sum_{n=1,3 \ldots}^{\infty} \frac{1}{n^{3}}\left(1-\frac{\cosh \left(\frac{n \pi x}{h}\right)}{\cosh \left(\frac{n \pi w}{2 h}\right)}\right) \sin \left(\frac{n \pi y}{h}\right)
$$

with $-w / 2<x<w / 2$ and $0<y<h$.

This allows to determine the component of the stress tensor $\Sigma$ of interest, i.e. $\sigma_{z y}=\eta \frac{\partial v_{z}}{\partial y}$, related to the wall shear stress at $y=0$ in the absence of cells :

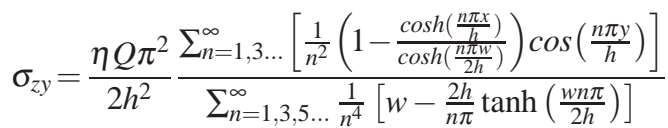

$Q$ is flow rate, $w$ and $h$ are respectively the channel width and height. $\sigma_{z y}$ is the stress felt by the cell if it were flat, since it corresponds to the main shear forces exerted by the fluid. We will see in the final section that this value can be affected by the presence of a cell. To determine the evolution of the Wall Shear Stress (WSS) in the microchannel, calculations were made using the Scilab software.

For a thin channel $(w \gg h)$, the equation (3) can be simplified and the WSS has an almost constant value across the channel $x$-axis (except in a narrow region close to the vertical edges) given by equation (4) and also shown in Fig. 3. 


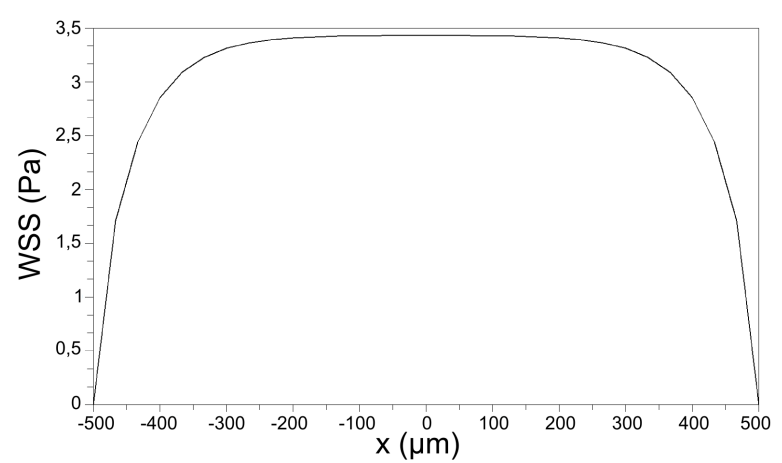

Fig. $3 \sigma_{z y}(x, 0, z)$ (WSS) at the bottom of a parallelepipedic channel $(w=1 \mathrm{~mm}, \mathrm{~h}=200 \mu \mathrm{m}, Q=$ $2.10^{-8} \mathrm{~m}^{3} \cdot \mathrm{s}^{-1}$ ). The WSS is almost constant accross the $x$ axis, except in the regions close to the vertical walls.

$$
\sigma_{z y}=\frac{6 \eta Q}{w h^{2}}
$$

This is usually a good assumption in our experiments, with $w$ of the order of $1 \mathrm{~mm}$ and $h$ ranging between 50 and $250 \mu m$.

\section{Data analysis}

Measurements were done on time-lapse images of the cells by drawing contours using a graphical pad (see Fig. 4). The plane of focus was chosen to be the plane of location of the cell-substrate contact area. The resolution of the images using a X20 microscope objective for such phase contrast images was 3.1pixels $/ \mu \mathrm{m}$ and a depth of field around $3 \mu \mathrm{m}$. Area (i.e. cell-substrate contact area), perimeter, circularity and ellipse parameters (axes, angle) were obtained using the ImageJ software (NIH Image, Bethesda, USA). Measurements were repeated several times and led to an uncertainty of 5\% maximum for the contact area. The cell area $A(t)$ was plotted versus time as shown for instance in Fig. 5 (flow rate increased every 5 minutes). $A(t)$ was fitted by a polynomial and the mean slope was calculated from this polynomial fit for each flow rate corresponding to a determined WSS. Thus the slope $\frac{d A}{d t}$ (corresponding to the area change) was plotted versus the WSS for each value of the applied flow rate or WSS giving rise to discrete data. Since the applied duration of each flow rate 
was short, this allowed to obtain sufficient data for determining the critical value of the WSS (i.e. $W S S_{c}$ ), this value being the WSS that gives a zero-slope, therefore a maximum in cell area.

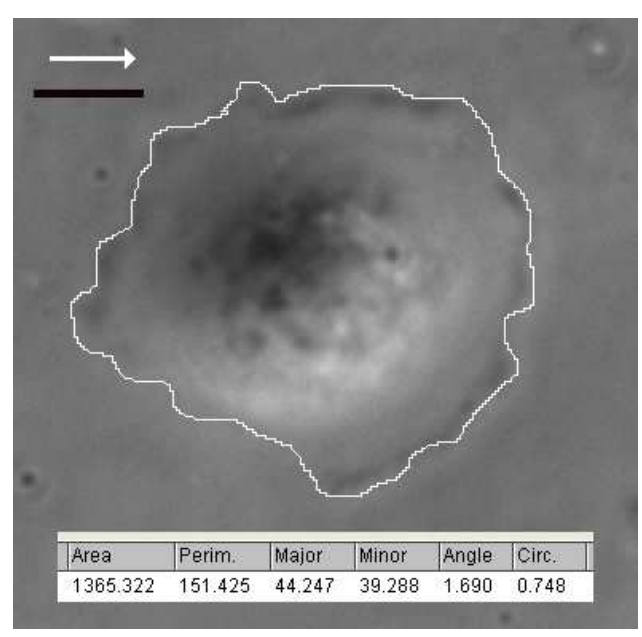

Fig. 4 Contour of T24 cell drawn with a graphic pad and measurement of cell parameters (area, perimeter, ellipse axes and orientation angle, circularity index defined as $\frac{4 \pi \text { area }}{\text { perimeter }}{ }^{2}$ ). The nucleus of the cell is surrounded by the lamellipodium. White arrow shows the flow direction. The black scale represents $10 \mu \mathrm{m}$. Channel dimensions: $h=82 \mu \mathrm{m}, w=1 \mathrm{~mm}$, WSS $=0.26 \mathrm{~Pa}$.

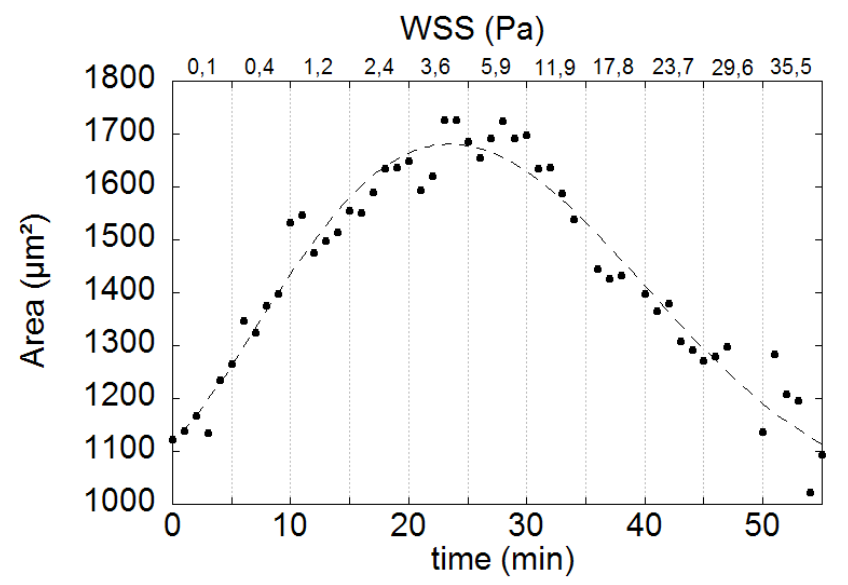

Fig. 5 Area versus time $A(t)$ for a T24 cell adhering to the bottom wall of a microchannel ( $w=1 \mathrm{~mm}$, $h=61 \mu \mathrm{m}$ ) and submitted to a flow increasing every 5 minutes. The black dots represent measurements using the ImageJ software (NIH Image, Bethesda, USA) and the thin dashed line is a polynomial fit. Wall shear stress values are given on the top axis. 
Immunofluorescence

Fluorescence experiments, based on immunofluorescence recognition of the paxillin molecule involved in the focal adhesion complexes, have been used to localize focal adhesions on the adherent cells submitted to flow in the microchannel. Fluorescence images were obtained with a $X 40$ microscope objective at 6 pixels $/ \mu \mathrm{m}$ resolution and a depth of field of roughly $2 \mu \mathrm{m}$. Cells have been fixed at different steps during the shear stress increase consisting of four plateaux, corresponding to wall shear stress values of $1 \mathrm{~Pa}, 3 \mathrm{~Pa}$, $5 \mathrm{~Pa}, 7 \mathrm{~Pa}$. Cells were fixed using PBS containing 3\% of Paraformaldehyde (PFA) for $10 \mathrm{~min}$. Membranes were permeabilized with PBS containing 0.5\% Triton X100 for $10 \mathrm{~min}$. Then the system was rinsed with PBS. A first wash was made with a solution of PBS containing $0.2 \%$ Saponine and 2\% BSA. A first antibody was used (human antipaxillin) for $30 \mathrm{~min}$, followed by a second wash (same as before). The second antibody TRITC (Tetramethyl Rhodamine Iso Thio Cyanate) was then used for $30 \mathrm{~min}$ under darkness conditions, followed by a third wash. The channel was then filled with a DAKO mounting medium. Microscopic observations were made using combined phase contrast and fluorescence, as shown in Fig. 6, where the first image is a phase contrast one used for identification of cell contour thus providing the area and the location of the center of mass, whereas the second one shows the location of paxillin, which appears mainly at the cell edges through several focal contacts. Fluorescence images were analyzed using the ImageJ software (NIH Image, Bethesda, USA): brighter pixels were selected using a threshold method (Fig. 6). Finally we used image processing to determine the number of adhesion zones (third image), their average area and their total size. In the end the uncertainties on the focal adhesion areas were found to be around $10 \%$.

\section{Results}

In order to understand how cells behave under flow conditions, we first need to have a reference which is the spreading behaviour with no applied flow. This will allow to determine relevant cell shapes and typical spreading times. Under static conditions, cells sediment, then they spread on the substrate (spreading does not occur at the same time for all cells). 


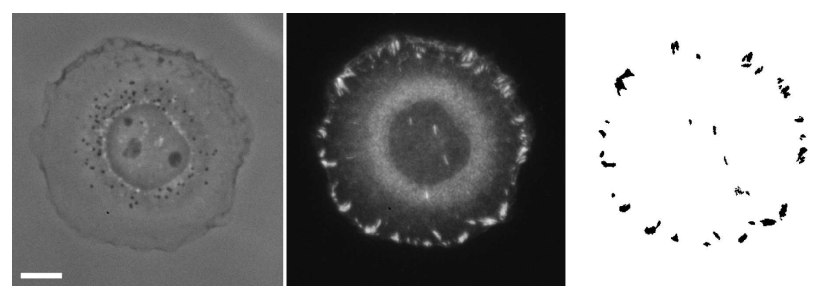

Fig. 6 Images of an adhering cell after application of successive stresses : Phase contrast image, immunofluorescence image of the paxillin molecules, corresponding focal adhesion zones obtained after image processing (maximum intensity levels only). The total number of adhesion zones is 31 and their average size is $2.5 \mu \mathrm{m}^{2}$, corresponding to a total adhesion area (sum) of $78 \mu \mathrm{m}^{2}$. The white scale bar represents $10 \mu \mathrm{m}$.

In most cases, spreading is fast and the maximum area is reached in less than 45 minutes as shown in Fig. 7a. After this spreading step, eventually followed by random migration on the substrate, some cells retract their protrusions (corresponding to the area decrease in Fig. 7a) to reach a round shape and divide into two daughter cells.
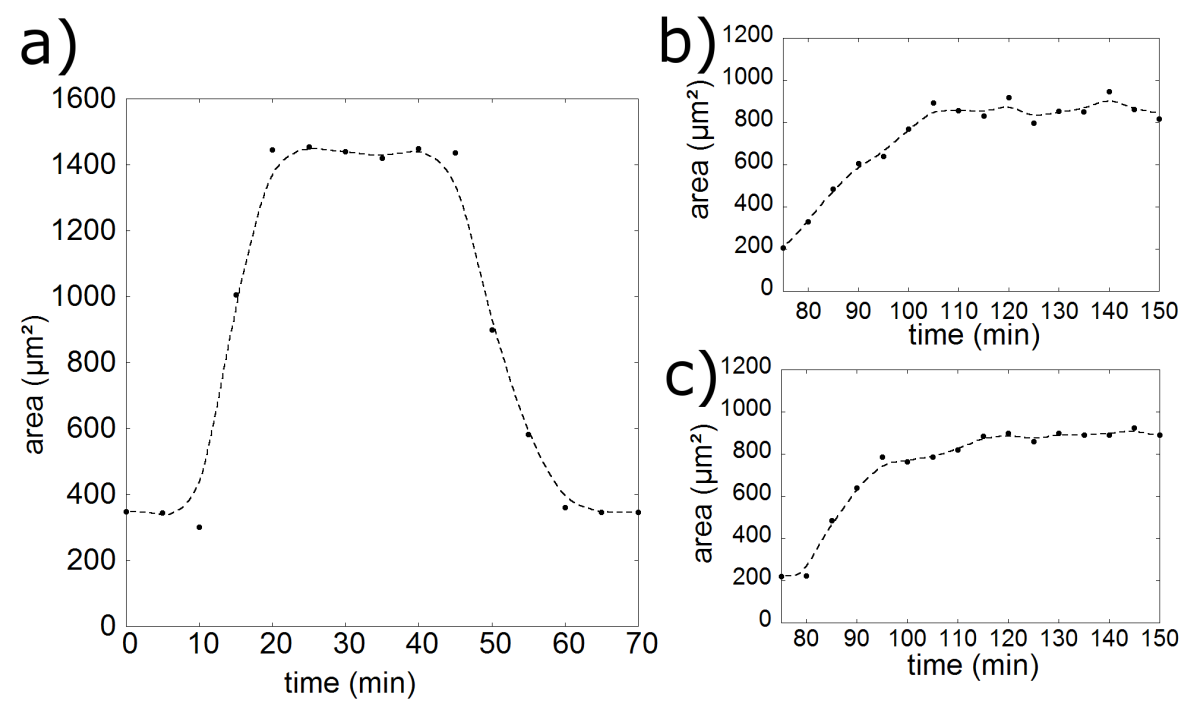

Fig. 7 T24 area in static conditions: a) Initial spreading is fast until reaching a plateau, then the area decreases just before cell division (time has been rescaled to $t=0$ corresponding to the beginning of spreading). b) and c) Areas of the two daughter cells after the cell has divided. The dashed lines guide the eye.

To take into account only viable cells, we decided to observe only daughter cells. Actually, a cell divides only when under good culture conditions, and cell division gives two healthy daughter cells. During the experiment in static conditions, eleven divisions were recorded, which means twenty-two daughter cells. For each division, the contour of the 
daughter cells was drawn and the cell areas were measured one hour after division. To decide which areas are to be selected, we determined the statistics of daughter cells population. The distribution of viable cells area is given in Fig. 8. Cell areas were in the range $800-1600 \mu \mathrm{m}^{2}$. The mean area was $1118 \pm 248 \mu \mathrm{m}^{2}$. This is the range that we selected in our experiments.

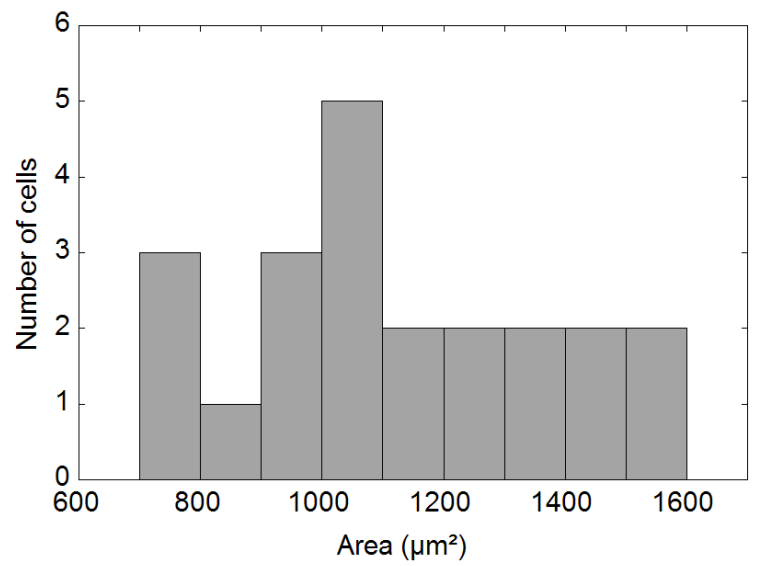

Fig. 8 Repartition of daughter cells' area in static conditions one hour after cell division.

T24 cells adherent at the bottom of microchannels were submitted to increasing shear flows. We observed a biphasic behaviour: cell area first increases at low WSS, then decreases for higher values of the WSS. Typical phase-contrast images are shown in Fig. 9. The cell first adheres and spreads along the channel wall as in Fig. 9(a)-(b), while keeping a round shape with a prominent nucleus and a large lamellipodium around it. As the flow rate is increased (i.e. WSS increases), the cell area starts to decrease (Figs 9(c)-(d)) until the cell eventually looses its adherence as shown in Fig. 9(e) just before detachment.

To analyze this data further, the time evolution of the area $A(t)$ of five cells is presented. Area versus time plots confirm that cell areas first increase at low WSS values (WSS values less than $3 \mathrm{~Pa}$ ), as it can be seen in Fig. 10 which illustrates the behaviour of five cells under the same flow conditions. Let us try to compare this behavior with the static case: in the static experiments, cells are left to divide. Once they divide, they are round and spread 

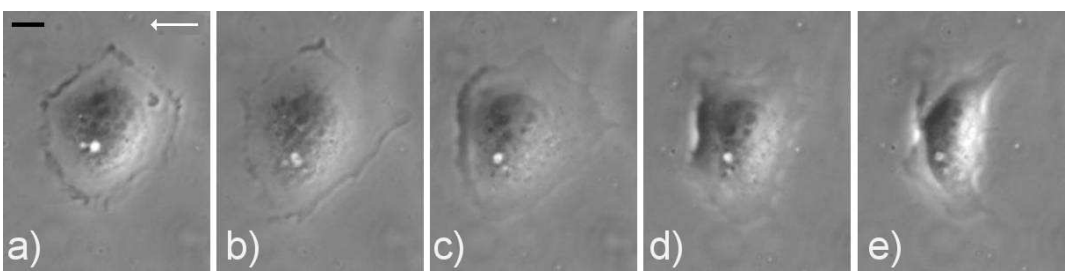

Fig. 9 Phase contrast images of a T24 cell adherent to the bottom of a microchannel $(w=1 \mathrm{~mm}, h=64 \mu \mathrm{m})$ submitted to an increasing shear flow. The white arrow shows the flow direction. The black scale represents $10 \mu \mathrm{m}$. a) WSS $=0.64 P a, \mathrm{~b}) \mathrm{WSS}=6.36 P a, \mathrm{c}) \mathrm{WSS}=19.1 P a, \mathrm{~d}) \mathrm{WSS}=31.7 \mathrm{~Pa}$, e) $\mathrm{WSS}=50.8 P a$

rapidly for $15 m n$ (up to $A=800 \mu m^{2}$ roughly as in Fig. 7(b)-(c)), then each daughter cell does not evolve in time very much (additional time of $50 \mathrm{mn}$ ). In the dynamic experiment, cells are first left to adhere for $15 \mathrm{mn}$; during this period they spread quite a bit (up to $A=$ $400-1200 \mu \mathrm{m}^{2}$ ). Then they are subjected to the increasing flow rates for $50 \mathrm{mn}$. So the conditions are not exactly the same, but cells seem to spread more under flow conditions. Therefore, they increase their contact area by increasing their number of focal adhesion sites. This will be explained in what follows.

When the WSS is increased further, cell area increases slowly until the area reaches a maximum (as shown by the stars in Fig. 10). When the WSS increases further, the area decreases with time. The maximum area corresponds to a zero-slope for $\frac{d A}{d t}$ i.e. the transition between positive and negative values of the area rate of change $\frac{d A}{d t}$ (as shown for example in Fig. 11 where the slope is plotted against the applied WSS). From the polynomial fit and its derivative, we determine the slopes $\frac{d A}{d t}$. We assume a constant slope for each 5 min time interval during which a constant WSS is applied $(0.1-29.6 P a)$ as in the example shown in Fig. 11. The slope cuts the zero axis at a critical value of the WSS (WSS ${ }_{c}$ ) corresponding to the maximum area (arrows in Fig. 11). Typical values of $\mathrm{WSS}_{c}$ are between 2 and $5 \mathrm{~Pa}$, as shown in Fig. 12.

To investigate the influence of the confinement, experiments were carried out (at least five cells) to measure Mean $\pm \mathrm{SD}$ of the $\mathrm{WSS}_{c}$ in channels with three different heights in the range $60-260 \mu \mathrm{m}$. Experimental data points in Fig. 12 represent average values of the $\mathrm{WSS}_{c}$ obtained in different microchannels whose heights were measured afterwards using SEM. Channel heights corresponding to one point were found to be slightly different, due to the UV exposure process used, but were within $5 \%$ maximum error. We found that $\mathrm{WSS}_{c}$ 


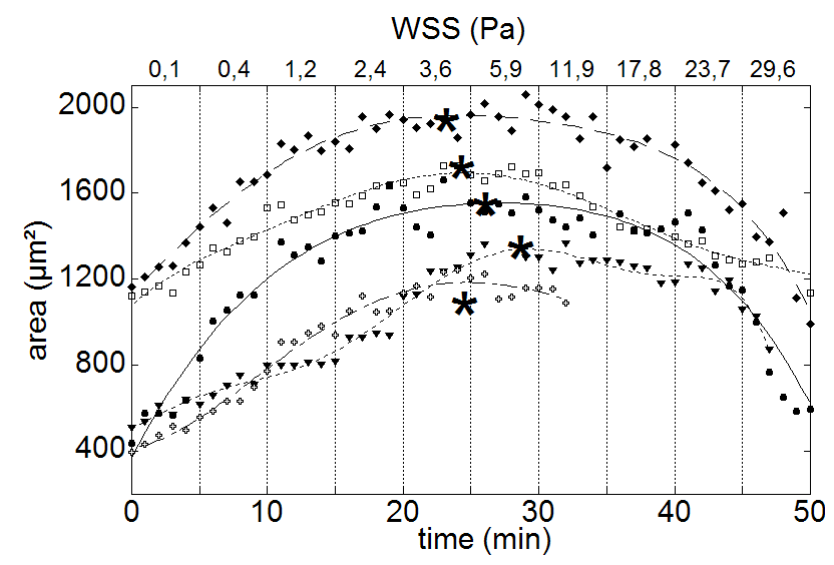

Fig. 10 Area evolution for five cells submitted to an increasing flow rate in a microchannel $(w=1 \mathrm{~mm}$, $h=61 \mu \mathrm{m}$ ). Corresponding WSS are given on the top axis. Symbols represent experimental data (measured from phase-contrast images of the cells), which have been fitted by a standard polynomial fit (lines). For each fit, the star indicates the maximum area.

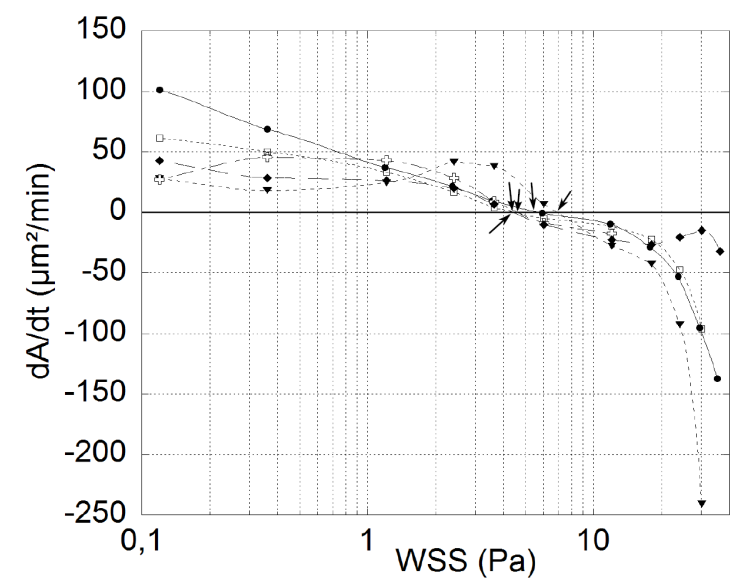

Fig. 11 Area change versus WSS for five cells submitted to an increasing flow rate in a microchannel ( $w=$ $1 \mathrm{~mm}, h=61 \mu \mathrm{m})$. Arrows correspond to the location of the cell maximum.

slowly increases when channel height increases as shown in Fig. 12. The three values that were chosen for the ratio $R / h$ correspond to a narrow channel $(R / h \sim 0.2)$, an intermediate one $(R / h \sim 0.1)$ and a deep channel $(R / h \sim 0.06)$, when using a cell height of roughly $15 \mu \mathrm{m}$. It is expected that a narrow channel will be more affected by the presence of the cell, acting as a blocking element, and that the velocity field will become three-dimensional [22]. This will affect the stresses exerted on the cell, and consequently the resulting force exerted by the flow field onto the adherent cell. We note from Fig. 12 that for small heights $h$, the 
critical stress $\mathrm{WSS}_{c}$ for the onset of detachment becomes smaller, this being due to the above idea that a smaller stress is needed to generate a similar resultant force in a narrow channel. In the 'modelling' part, we will use the model of Gaver \& Kute [22] to justify quantitatively this data.

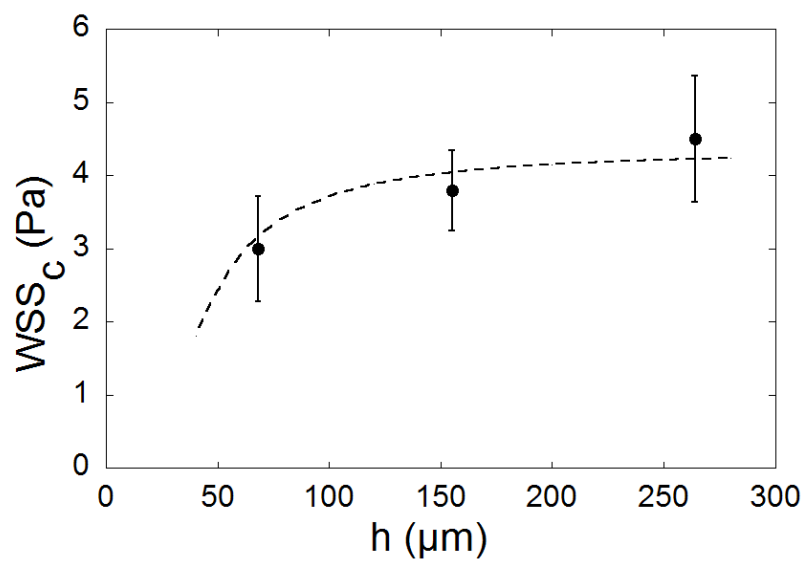

Fig. $12 \mathrm{WSS}_{c}$ vs. channel height $h$ (at constant $w=1 \mathrm{~mm}$ ). Data are the mean of the $\mathrm{WSS}_{c}$ measured for all the cells tested in the experiments $(10,5$ and 6 cells for the channels with average heights 68,155 and $264 \mu \mathrm{m}$ respectively). The dashed lines are the fit of the results based on the model presented in the discussion: experimental values (black dots) are fitted with the hypothesis of equilibrium between adhesion and hydrodynamic forces: $F_{\text {flow }}=F_{a d_{z}}$. Results of the fit give : $N f_{a d h}=12 n N$. Error bars are standard errors to the mean.

In order to localize focal adhesions and study their evolution when fluid stress is increased, we carried out immunofluorescence experiments (see "Materials and Methods") after fixing the T24-cells which have undergone different shear stresses. This allowed to determine the position and size of focal adhesion areas for cells fixed either after the first plateau at $1 \mathrm{~Pa}$, or after the second plateau at $3 \mathrm{~Pa}$, or the third one at $5 \mathrm{~Pa}$, or the last one at $7 \mathrm{~Pa}$. It appears clearly from these observations that focal adhesions are mostly located in the periphery of the cell, as shown in Fig. 6. Mean area of focal zones was nearly constant, around $1 \mu \mathrm{m}^{2}$, independent of the maximum shear stress the cell experienced (Fig. 13).

Our data in Fig. 14 show that the ratio of area occupied by focal zones over the whole cell contact area is higher for cells sheared until $3 \mathrm{~Pa}$. This wall shear stress value is close to the critical wall shear stress obtained for cells in a channel of similar size (see Fig. 12). 


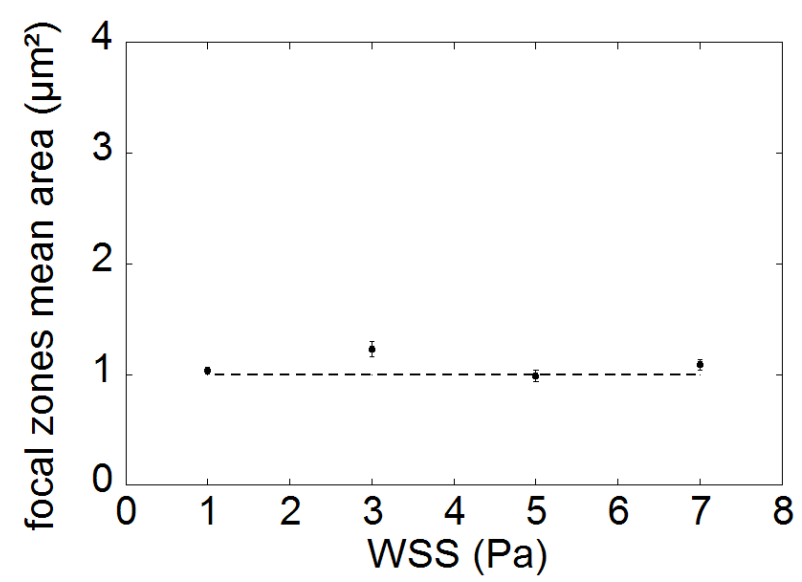

Fig. 13 Mean focal adhesions vs. maximum shear stress experienced on cells adherent in microchannels $(w=$ $1 \mathrm{~mm}, \mathrm{~h}=231 \mu \mathrm{m})$. The flow rate, increased every 5 minutes, has generated an increasing wall shear stress: cells $(33,24,24$ and 31$)$ were submitted to this increasing shear stress up to 1, 3, 5 and 7 Pa respectively. The dashed line guides the eye. Error bars are standard errors to the mean.

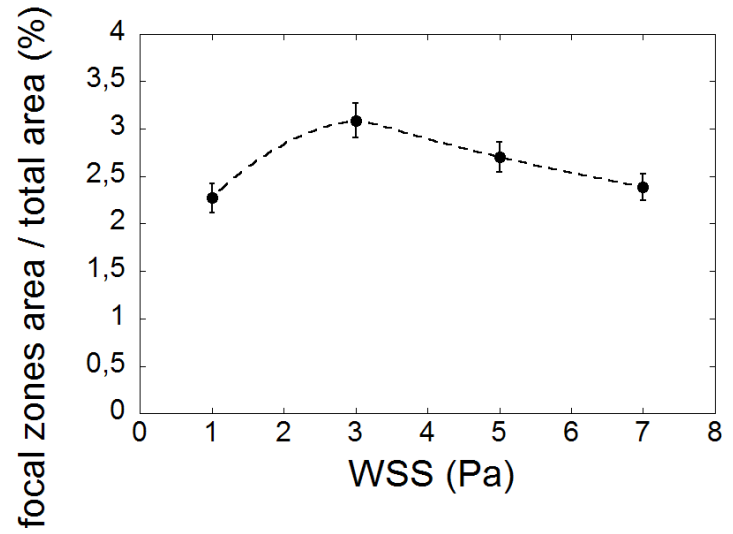

Fig. 14 Area fraction occupied by focal zones on adherent cells in microchannels $(w=1 \mathrm{~mm}, h=231 \mu \mathrm{m})$ vs. maximum shear stress experienced. The flow rate, increased every 5 minutes, has generated an increasing wall shear stress: $35,33,24$ and 31 cells were submitted to a shear stress until 1, 3, 5 and $7 \mathrm{~Pa}$ respectively. The dashed line guides the eye. Error bars are standard errors to the mean.

We have then studied the spatial distribution of focal zones with respect to the direction of flow, that we chose to be the reference angle, as explained in Fig. 15.

Data treatment allowed to determine the total area corresponding to focal adhesions in each angular sector of $20^{\circ}$. Results have been plotted on the polar diagram in Fig. 16. One can see the evolution and localisation of the focal contacts around the cell, as the shear stress is increased: 


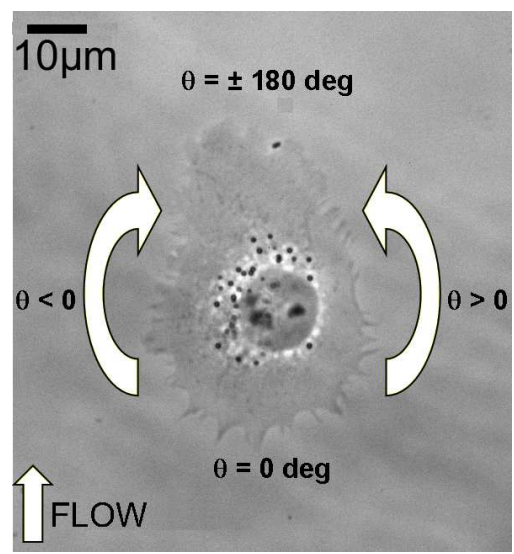

Fig. 15 Direction of flow and definition of the angle $\theta$ to locate the position of focal adhesion zones. $\theta=0^{\circ}$ corresponds to the point of the cell which faces the flow. $\theta$ takes values between 0 and $-180^{\circ}$ on the left part, and 0 and $180^{\circ}$ on the right part. Flow is from bottom to top, as indicated by the arrow.

- At low shear stress $(1 \mathrm{~Pa})$, focal zones represent between 2 and $3 \mu \mathrm{m}^{2}$ per angular sector of $20^{\circ}$, with no prefered direction.

- When the shear stress is increased further (until $3 P a$ ), focal zones localize on the upstream side of the cell, which faces the flow, while in the back, their cumulative area decreases.

- Cells submitted to an increasing shear flow until $5 \mathrm{~Pa}$ reinforce their focal adhesions on the lateral edges, where they reach nearly $5 \mu \mathrm{m}^{2}$.

- For the highest values of the shear stress (up to $7 \mathrm{~Pa}$ ), focal adhesions localize again symmetrically with respect to the direction of flow, nonetheless their number decreases (about $2 \mu \mathrm{m}^{2}$ per angular sector of $20^{\circ}$ ).

\section{Modelling}

We need to correlate the WSS to the adhesion resistance, i.e. the forces generated by cells adhering at the wall to resist the flow. In confined geometries, the fluid is constrained by the channel walls, which leads to an increase in the flow resistance when an object partially blocks the channel (see Fig. 2). Consequently, the full Navier-Stokes equations need to be solved for the components of the velocities, which now are in all three directions. This analysis was carried out in 2D [22] using finite element method and lubrication theory pre- 
a) $1 \mathrm{~Pa}$

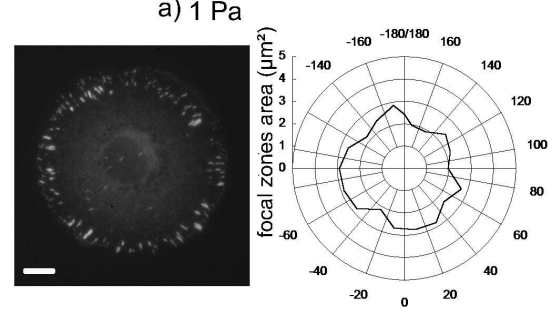

c) $5 \mathrm{~Pa}$

b) $3 \mathrm{~Pa}$

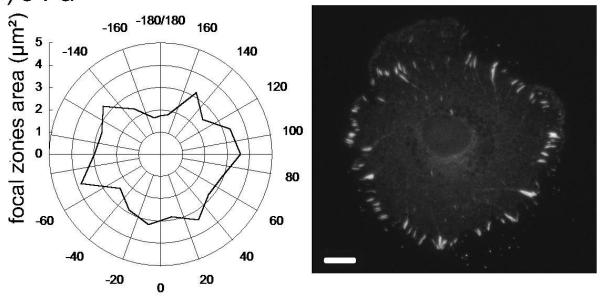

d) $7 \mathrm{~Pa}$
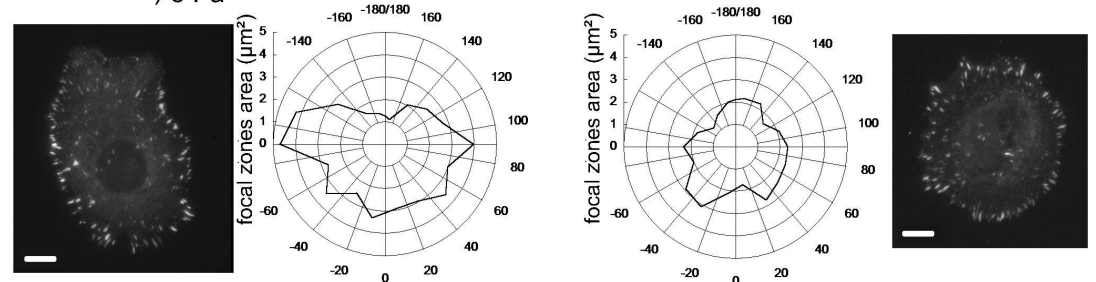

Fig. 16 Evolution of the mean angular localization of focal complexes for T24 adherent cells with increasing values of the wall shear stress: a) $1 P a$, b) $3 P a$, c) $5 P a$, d) $7 P a$. The cumulative area of the focal zones is determined for each angular sector $\left(20^{\circ}\right)$. The orientation of the adhesion spots refers to the angle $\theta$, whose origin corresponds to the cell locus facing the flow (see Fig. 15). A typical fluorescent image (scale bar is $10 \mu \mathrm{m}$ long) is shown as an example of the corresponding diagram.

dictions. The results obtained provide simple formulas of the force $\overrightarrow{F_{\text {flow }}}$ and torque $\overrightarrow{T_{\text {flow }}}$ applied to the cell, after integration of the full stress field over the cell boundary, considered as a semi-spherical bulge (radius $R$ ) attached to the bottom of a narrow channel (height $h$ ). The force and the torque values (around the axis going through the center of mass) induced by the flow have been generalized from 2D-simulations to the 3D-case [22]. Explicit formulas for such force and torque are given by:

$$
\begin{gathered}
\overrightarrow{F_{\text {flow }}}=24 \eta \gamma^{2} \frac{Q}{w} \frac{3.19+0.65 \gamma+4.34 \gamma^{2}}{\left(1-\gamma^{2}\right)^{5 / 2}} \overrightarrow{e_{z}} \\
\overrightarrow{T_{\text {flow }}}=12 \pi \eta \gamma^{2} \frac{R Q}{w} \frac{1.15+0.7 \gamma}{\left(1-\gamma^{2}\right)^{5 / 2}} \overrightarrow{e_{x}}
\end{gathered}
$$

where $\eta$ is the fluid viscosity, $R$ the cell radius, $Q$ the flow rate, and $\gamma=\frac{R}{h}$ is the degree of confinement ( $h$ being the channel height). Several experimental situations have also shown that these formulas are quite accurate. The former analysis [22] has been investigated further in recent years from a numerical point of view $[6,48,53]$, but not so much experimentally. 
It is important to realize that the 'local shear stress' may take values much higher than the ones without the cell. In some cases like $R / h=0.1$ for example (small obstruction), the shear stress at the top of the cell can be three times larger than the stress at the wall (see Fig. 5 of reference [22]). This will have an effect on the total force $\overrightarrow{F_{f l o w}}$ which is already taken into account in Eq.(5), but this effect will not be as drastic as for the local stress.

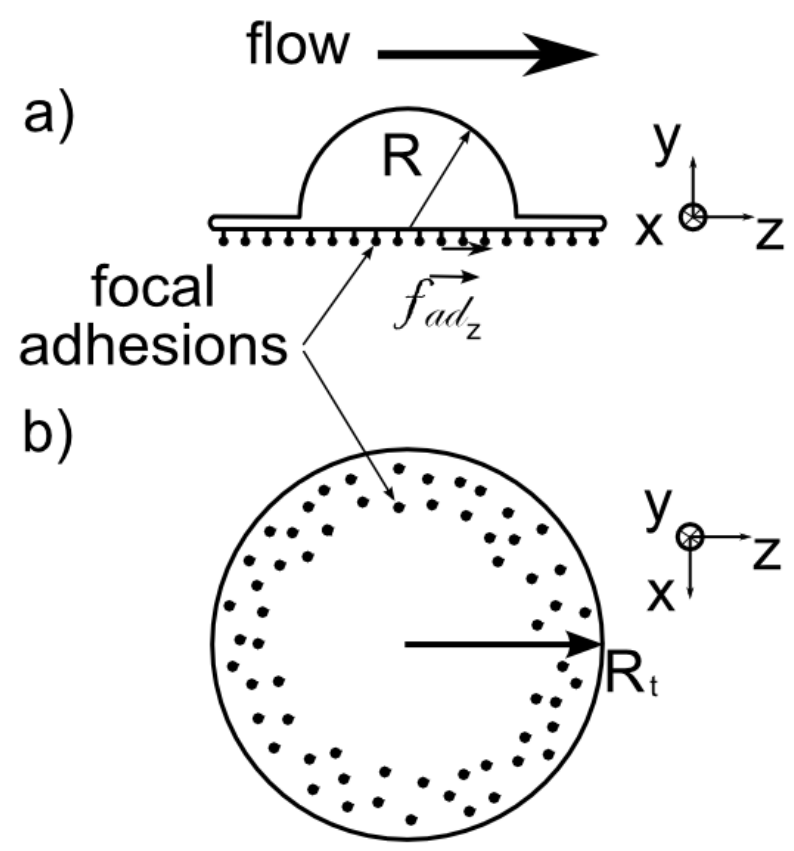

Fig. 17 Schematic views of a cell adhering to a flat surface submitted to a shear flow (flow is from left to right). a) Side view: the cell is modeled as a half-sphere (radius $R$ ), with a circular lamellipodium (radius $R_{t}$ ). An adhesive force along $z$ with magnitude $f_{a d_{z}}$ is applied to each one of the $N$ focal adhesion sites. b) Bottom view: dots represent focal adhesion sites, where the individual forces are exerted.

Since the cell area decreases above a certain typical hydrodynamic force, we conclude that, above this typical value of the hydrodynamic stress, bonds are more likely to break than to form, leading to a decrease in total adhesive force. Thus there exists an equilibrium between the effect of hydrodynamic forces and adhesive forces, corresponding to the critical stress that was determined earlier. We will restrict our analysis to the influence of the force (and not the torque), as it seems that during the experiments, cells remain bound to the substrate and do not seem to be affected by lift effects, or at least not before the end when the 
ultimate detachment occurs. It is probably true that when the highest stresses $(20-30 P a)$ are involved, membrane 'rufling' and 'peeling' of bounds may start, in relation with the values of the torques. The hydrodynamic force is given in equation (5). The force due to the adhesive resistance of the cell that counterbalances the hydrodynamic force is now investigated. We consider a cell as a half-sphere of radius $R$, and assume a distribution of $N$ adhesion sites on the whole cell-substrate contact area $S$, which is supposed to be circular (radius $R_{t}$ ). An estimation of $R_{t}$ was obtained in the experiments $R_{t} \sim 26 \pm 2 \mu \mathrm{m}$, as will be justified later. A force $\overrightarrow{f_{a d}}$ (which can be decomposed into a vertical component $f_{a d_{y}} \overrightarrow{e_{y}}$ and an horizontal component $f_{a d_{z}} \overrightarrow{e_{z}}$ ) is applied at each focal adhesion site (see Fig. 6). The total adhesion force $\overrightarrow{F_{a d}}$ is the sum of the individual forces $\overrightarrow{f_{a d}}: \overrightarrow{F_{a d}}=\sum \overrightarrow{f_{a d}}$, and its components can be determined by summing the components of individual adhesion forces as done in the system (7):

$$
\left\{\begin{array}{l}
F_{a d_{z}}=\sum f_{a d_{z}}=N f_{a d_{z}} \\
F_{a d_{y}}=\sum f_{a d_{y}}=N f_{a d_{y}}
\end{array}\right.
$$

When in equilibrium, adhesion forces counterbalance hydrodynamic effects and the cell does not spread any longer but still holds onto the substrate, therefore the hydrodynamic force $\overrightarrow{F_{\text {flow }}}$, which is along the $z$ axis $\left(\overrightarrow{F_{\text {flow }}}=F_{\text {flow }} \overrightarrow{e_{z}}\right)$, is balanced by the horizontal component of the adhesion force $F_{a d_{z}}$ :

$$
F_{\text {flow }}=F_{a d_{z}}
$$

Using the hydrodynamic force estimation (in Eq. 5) together with Eq.(8), the cell being represented by a semi-circular bulge of radius $R=15 \mu \mathrm{m}$ we then obtain at equilibrium:

$$
24 \eta\left(\frac{R}{h}\right)^{2} \frac{Q}{w} \frac{3.19+0.65 \frac{R}{h}+4.34\left(\frac{R}{h}\right)^{2}}{\left(1-\left(\frac{R}{h}\right)^{2}\right)^{5 / 2}}=N f_{a d_{z}}
$$


where $W S S=6 \eta Q / w h^{2}$ appears and can be replaced by the shear stress at the wall (case without cell) from equation (4). The critical value of the WSS then becomes:

$$
W S S_{c}=N f_{a d_{z}} \frac{1}{4 R^{2}} \frac{\left(1-\left(\frac{R}{h}\right)^{2}\right)^{5 / 2}}{3.19+0.65 \frac{R}{h}+4.34\left(\frac{R}{h}\right)^{2}}
$$

The values of $\mathrm{WSS}_{c}$ versus $h$ have been estimated for three values of the adhesion parameter $N f_{a d_{z}}=10 n N, 20 n N$ and $30 n N$ using $R=15 \mu m$. Results are shown in Fig. 18.

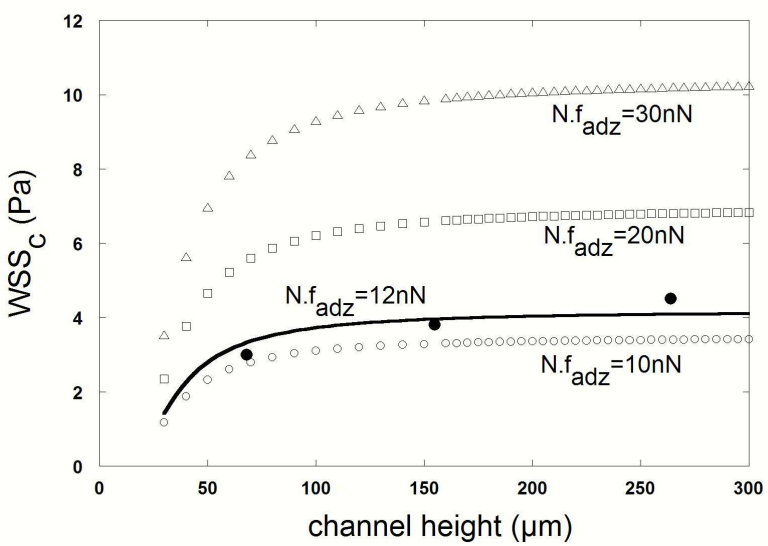

Fig. $18 \mathrm{WSS}_{c}$ versus $h$ calculated with equation (10) for different values of the $N f_{a d}$ parameter. $R=15 \mu \mathrm{m}$. Also shown are the data points and the best fit leading to $N f_{a d_{z}}=12 n N$.

For small channels $(h<100 \mu m)$, the WSS increases rapidly with channel height $h$. The increase for higher channels is much slower and shows a plateau when $h$ becomes large: $W S S_{c}=\frac{N f_{a d_{z}}}{12.76 R^{2}}$. This is in agreement with our experimental data: for the three channel sizes used in the experiments, $\mathrm{WSS}_{c}$ increases with $h$. Fitting of the experimental data with the results of the model (10) has been carried out using $N f_{a d_{z}}$ as a variable parameter (see Fig. 12). Results give a good correlation (using $R=15 \mu \mathrm{m}$ as an estimation of the cell height), corresponding to an approximate horizontal component of the adhesion force $F_{a d_{z}}=N f_{a d_{z}}=$ $12 n N$. 
Thus our modeling approach leads to the total adhesion force component in the plane corresponding to the cell-substrate contact $F_{a d_{z}}=12 \mathrm{nN}$. Although cell adhesion properties are cell and matrix-dependent [56], estimates of the forces involved can be discussed. Different techniques have been elaborated to determine cell traction forces exerted by cells on a given substrate. For example, the displacement of fluorescent beads embedded in a soft polyacrylamide gel onto which cells adhere allow to determine the traction field, i.e. the local force per unit area (or per unit adhesion site) imposed by the cell. Maximum traction forces for T24 cells, HASM cells, and 3T3 fibroblasts spread on polyacrylamide gels (elasticity modulus in the range $1-10 \mathrm{kPa}$ ) have been found to be respectively $0.14 \mathrm{kPa}$ [1], $0.4 \mathrm{kPa}$ [5] and $7 \mathrm{kPa}$ [17]. As it can be seen on fluorescent images [40,3,2], focal adhesion sizes are usually in the range $\left[1-5 \mu \mathrm{m}^{2}\right]$. These observations lead to traction forces between $0.05 \mathrm{nN}$ and $10 n N$ per focal adhesion site. Note that in recent work [14], measurements of traction forces $(\sim 0.25 \mathrm{kPa})$ were also made on L929 fibroblasts adhering in microchannels subjected to similar wall shear stresses in the range $[1.5-4.7 P a]$. Table 1 gives a summary of the different values available from this literature, usually stresses are available (i.e. binding force per unit area), therefore using the typical adhesion size of complexes from above one gets the binding force per focal adhesion (FA). Finally, the total binding force is obtained using an approximate number of forty adhesion complexes [40].

\begin{tabular}{|c|c|c|c|c|c|}
\hline & T24 & T24 & HSAM & 3 T3 & L929 \\
\hline Reference & This work & {$[1]$} & {$[5]$} & {$[17]$} & {$[14]$} \\
\hline Gel elasticity & $0.6 \mathrm{MPa}$ & $6.3 \mathrm{kPa}$ & $1.2 \mathrm{kPa}$ & $6.2 \mathrm{kPa}$ & $9.8 \mathrm{kPa}$ \\
\hline Total binding force & $12 \mathrm{nN}$ & $5.5-28 \mathrm{nN}$ & $16-80 \mathrm{nN}$ & $280-1400 \mathrm{nN}$ & $10-50 \mathrm{nN}$ \\
\hline Binding force per FA & $0.27 \mathrm{nN}$ & $0.14-0.7 \mathrm{nN}$ & $0.4-2 \mathrm{nN}$ & $7-35 \mathrm{nN}$ & $0.25-1.25 \mathrm{nN}$ \\
\hline Stress & $0.27 \mathrm{kPa}$ & $0.14 \mathrm{kPa}$ & $0.4 \mathrm{kPa}$ & $7 \mathrm{kPa}$ & $0.25 \mathrm{kPa}$ \\
\hline
\end{tabular}

Table 1. Available or estimated values of the adhesion parameters for different cell types using approximate focal adhesion (FA) sizes $\left[1-5 \mu m^{2}\right]$.

Other studies using cells adhering to flexible micropillars give access to the same traction forces, correlated to focal adhesion sites located on the top of such micropillars. Fibrob- 
lasts and smooth muscle cells grown on such PDMS microposts develop cellular traction forces comprised between $1 n N$ and $10 n N$ [31,2], whereas for individual epithelial cells migrating on micropillars [21], maximal forces reached $3 n N$. Although the present situation is not that of a migrating cell, it can be useful to compare the data given above to our case, since it is important to find out how much traction resistance a cell can exert on such a substrate. Based on the number of focal adhesions (45 on average) and their size $\left(1 \mu \mathrm{m}^{2}\right.$ as seen in Fig. 13), we can estimate the average force per focal site to be about $0.27 n N$, or an equivalent stress of about $270 \mathrm{~Pa}$ at each focal adhesion site. If we now consider the analogy between the development of resistance stresses and the traction stresses developed during migration, it is probably true that the stresses obtained in the current study are typical ones at stable focal adhesions; they should be in the range of the maximum ones found during migration. Indeed, during migration, cells stop and rest, then they start pulling again and develop larger stresses from time to time [1] after they have formed stable adhesions. The stresses found here are in the range of the maximum stresses found for migrating T24cells [1] on a $10 \mathrm{kPa}$-substrate, where a maximum value of $200 \mathrm{~Pa}$ was found for the traction stress. In the present case, the PDMS Young's modulus used for the microchannel is roughly $0.6 \mathrm{MPa}$. Therefore, the microchannel results overestimate this value. Finally, let us note that the forces exerted by such cancer cells are rather small, as compared to fibroblasts [2]. They compare better with values found for HASM cells [5].

Therefore our method is quite powerful to apply controlled shear forces using a flow field and, combined with fluorescent microscopy, it can lead to the determination of traction resistance exerted by the cell through its focal contacts.

\section{Conclusions}

A microfluidics experiment has been carried out to detach cancer cells adhering to the bottom of a micro-fabricated channel. The analysis of the cell morphology has clearly revealed the cell resistance to increasing flow, until a critical stress was reached. This critical stress is a function of the product of the number of adhesion sites with their strength, as well as the confinement ratio. When confinement increases, the critical shear stress decreases, whereas 
it reaches a constant limit for high channels. This rather simple experiment was combined with fluorescent assays to allow the determination of the forces developed at each focal adhesion site. Although this analysis contains estimates, it can predict adhesion parameters rather well, when compared to previous studies related to traction forces exerted by adhering/migrating cells. It also confirms a previous result showing that such cancer cells exert small forces, therefore they may move faster. Further fluorescence studies are now needed to correlate more precisely the temporal and spatial distribution of adhesion sites (size, number) as a function of the applied shear stress.

\section{Acknowledgments}

The authors thank the European Commission Marie Curie Research Training Network MRTNCT-2004-503661 "Modelling, mathematical methods and computer simulation of tumour growth and therapy" for its support. Image acquisition was performed using the microscopy facility at the "Institut Albert Bonniot". This equipment was partly funded by "Association pour la Recherche sur le Cancer" (Villejuif, France) and the "Nanobio program". We are also thankful to V. M. Laurent for helpful discussions and reading of the manuscript.

\section{References}

1. Ambrosi D, Duperray A, Peschetola V, Verdier C (2009) Traction patterns of tumor cells. J. Math. Biol. 58:163-181

2. Balaban NQ, Schwarz US, Riveline D, Goichberg P, Tzur G, Sabanay I, Mahalu D, Safran S, Bershadsky A, Addadi L, Geiger B (2001) Force and focal adhesion assembly: a close relationship studied using elastic micro-patterned substrates. Nat. Cell Biol. 3:466-472

3. Bershadsky AD, Balaban NQ, Geiger B (2003) Adhesion-dependent cell mechanosensitivity. Annu. Rev. Cell Dev. Biol. 19:677-695

4. Bohnet S, Ananthakrishnan R, Mogilner A, Meister JJ, Verkhovsky AB (2006) Weak force stalls protrusion at the leading edge of the lamellipodium. Biophys. J. 90:1810-1820

5. Butler JP, Tollic-Norrelykke IM, Fabry B, Fredberg J (2002) Traction fields, moments, and strain energy that cells exert on their surroundings. Am. J. Physiol. 282:C595-C1605

6. Cao J, Donell B, Deaver DR, Lawrence MB, Dong C (1998) In vitro side-view imaging technique and analysis of human T-leukemic cell adhesion to ICAM-1 in shear flow. Microvasc. Res. 55:124-137 
7. Chachisvilis M, Zhang YL, Frangos JA (2006) G-protein coupled receptors sense fluid shear stress in endothelial cells. Proc. Natl. Acad. Sci. USA 103:15463-15468

8. Chaw KC, Manimaran M, Tay EH, Swaminathan S (2007) Multi-step microfluidic device for studying cancer metastasis. Lab Chip 7:1047-1047

9. Chen CS (2008) Mechanotransduction - a field pulling together. J. Cell Science 121:3285-3292

10. Chotard-Ghodsnia R, Drochon A, Faucheux N, Nagel MD, Grebe R (2002) Effect of shear stress and of transmural pressure on cAMP-dependent responses of cells adhering to a biomaterial. Eur. Phys. J. AP $17: 155-162$

11. Chotard-Ghodsnia R, Haddad O, Leyrat A, Drochon A, Verdier C, Duperray A (2007) Morphological analysis of tumor cell/endothelial cell interactions under shear flow. J. Biomech. 40:335-344

12. Coughlin MF, Schmid-Schönbein GW (2004) Pseudopod projection and cell spreading of passive leukocytes in response to fluid shear stress. Biophys. J. 87:2035-2042

13. Dalous J, Burghardt E, Müller-Taubenberger A, Bruckert F, Gerisch G, Bretschneider T (2008) Reversal of cell polarity and actin-myosin cytoskeleton reorganization under mechanical and chemical stimulation. Biophys. J. 94:1063-1074

14. Das T, Maiti TK, Chakraborty (2008) Traction force microscopy on-chip: shear deformation of fibroblast cells. Lab. Chip 8:1308-1318

15. De R, Zemel A, Safran SA (2007) Dynamics of cell orientation. Nature Physics 3:655-659

16. Decave E, Garrivier D, Bréchet Y, Fourcade B, Brückert F (2002) Shear flow-induced detachment kinetics of dictyostellium discoideum cells from solid substrate. Biophys. J. 82:2383-2395

17. Dembo M, Wang YL (1999) Stresses at the cell-to-substrate interface during locomotion of fibroblasts. Biophys. J. 76:2307-2316

18. Discher DE, Janmey P, Wang Y (2005) Tissue cells feel and respond to the stiffness of their substrate. Science : $310: 1139-1143$

19. Dong C, Lei XX (2000) Biomechanics of cell rolling: shear flow, cell-surface adhesion, and cell deformability. J. Biomech. 33:35-43

20. Duffy DC, Cooper McDonald J, Schueller OJA, Whitesides GM (1988) Rapid prototyping of microfluidic systems in poly(dimethylsiloxane). Anal. Chem. 70:4974-4984

21. du Roure O, Saez A, Buguin A, Austin RH, Chavrier P, Silberzan P, Ladoux B (2005) Force mapping in epithelial cell migration. Proc. Natl. Acad. Sci. USA 102:2390-2395

22. Gaver DP, Kute SM (1988) A theoretical model study of the influence of fluid stresses on a cell adhering to a microchannel wall. Biophys. J. 75:721-733

23. Gutierrez E, Groisman A (2007) Quantitative measurements of the strength of adhesion of human neutrophils to a substratum in a microfluidic device. Anal. Chem. 79:2249-2258

24. Hammer DA, Lauffenburger DA (1987) A dynamical model for receptor-mediated cell adhesion to surfaces. Biophys. J. 52:475-487 
25. House SD, Lipowsky HH (1998) In vivo determination of the force of leukocyte-endothelium adhesion in the mesenteric microvasculature of the cat. Circ. Res. 63:658-668

26. Ingber DE (2003) Mechanobiology and diseases of mechanotransduction. Ann. Med. 35:564-577

27. Irima D, Charras G, Agrawal N, Mitchison T, Toner M (2007) Polar stimulation and constrained cell migration in microfluidic channels. Lab Chip 7:1783-1790

28. Jin Q, Verdier C, Singh P, Aubry N, Chotard-Ghodsnia R, Duperray A (2007) Migration and deformation of leukocytes in pressure driven flows. Mechanics Res. Commun. 34:411-422

29. Kwon KW, Choi SS, Lee SH, Kim B, Lee SN, Park MC, Kim P, Hwang SY, Suh KY (2007) Label-free, microfluidic separation and enrichment of human breast cancer cells by adhesion difference. Lab Chip 7:1461-1468

30. Lawrence MB, Springer TA (1991) Leukocytes roll on a selectin at physiological flow rates: Distinction from and Prerequisite for Adhesion through lntegrins. Cell 65:859-873

31. Li B, Xie L, Starr ZC, Yang Z, Lin JL, Wang JHC (2007) Development of micropost force sensor array with culture experiments for determination of cell traction forces. Cell Motil. Cytoskeleton 22:509-518

32. Lo CM, Wang HB, Dembo M, Wang YL (2000) Cell movement is guided by the rigidity of the substrate. Biophys. J. 79:144-152

33. Lu H, Koo LY, Wang WM, Lauffenburger DA, Griffith LG, Jensen KF (2004) Microfluidic shear device for quantitative analysis of cell adhesion. Anal. Chem. 76:5257-5264

34. Makino A, M, Bokoch GM, Chien S, Schmid-Schönbein GW (2005) Control of neutrophil pseudopods by fluid shear: role of Rho family GTPases. Am. J. Physiol. 863:C871-C1674

35. Miles FL, Pruitt FL, van Golen KL, Cooper CR (2007) Stepping out of the flow: capillary extravasation in cancer metastasis. Clin. Exp. Metastasis online first

36. Moazzam F, DeLano FA, Zweifach B, Schmid-Schönbein GW (1997) The leukocyte response to fluid stress. Proc. Natl. Acad. Sci. USA 94:5338-5343

37. Munevar S, Wang YL, Dembo M (2001) Distinct roles of frontal and rear cell-substrate adhesions in fibroblast migration. Mol. Biol. Cell 12:3947-3954

38. Okada T, Okuno H, Mitsui H (1994) A novel in vitro assay system for transendothelial tumor cell invasion: significance of E-selectin and alpha 3 integrin in the transendothelial invasion by HT1080 fibrosarcoma cells. Clin. Exp. Metastasis 12:305-314

39. Orr AW, Helmke BP, Blackman BR, Schwartz MA (2006) Mechanisms of mechanotransduction. Dev. Cell 10:11-20

40. Paul R, Heil P, Spatz JP, Schwartz US (2008) Propagation of mechanical stress through the actin cytoskeleton toward focal adhesions: model and experiment. Biophys. J. 94:1470-1482

41. Pierres A, Benoliel AM, Bongrand P (1995) Measuring the lifetime of bonds made between surfacelinked molecules. J. Biol. Chem. 270:26586-26592

42. Pozrikidis, C. Shear flow over a protuberance on a plane wall. J. Eng. Math. 31:29-42, 1997. 
43. Reinhart-King CA, Dembo M, Hammer DH (2005) The dynamics and mechanics of endothelial cell spreading. Biophys. J. 89:676-689

44. Riveline D, Zamir E, Balaban NQ, Schwarz US, Ishizaki T, Narumiya S, Kam Z, Geiger B, Bershadsky AD (2001) Focal contacts as mechanosensors: externally applied local mechanical force induces growth of focal contacts by an mDia1-dependent and ROCK-independent mechanism. J. Cell. Biol. 153:11751186

45. Saadi W, Wang SJ, Lin F, Jeon NL (2006) A parallel-gradient microfluidic chamber for quantitative analysis of breast cancer cell chemotaxis. Biomed. Microdev. 8:109-118

46. Schwartz MA, DeSimone DW (2008) Cell adhesion receptors in mechanotransduction. Curr. Opin. Cell Biol. 20:551-556

47. Springer TA (1994) Traffic signals for lymphocyte recirculation and leukocyte emigration: the multistep paradigm. Cell 76: 301-314

48. Sugihara-Seki M (2001) Flow around cells adhered to a microvessel wall. II: Comparison to flow around adherent cells in channel flow. Biorheology 38:3-13

49. Théry M, Racine V, Piel M, Pépin A, Dimitrov A, Chen Y, Sibarita J, Bornens M (2006) Anisotropy of cell adhesive microenvironment governs cell internal organization and orientation of polarity. Proc. Natl. Acad. Sci. USA 103:19771-19776

50. Thoumine O, Ziegler T, Girard PR, Nerem RM (1995) Elongation of confluent endothelial cells in culture: the importance of fields of force in the associated alterations of their cytoskeletal structure. Exp. Cell Research 219:427-441

51. Verdier C (2003) Review. Rheological properties of living materials: From cells to tissues. J. Theor. Med. 5:67-91

52. Verdier C, Couzon C, Duperray A, Singh P (2009) Modelling cell interactions under flow. J. Math. Biol. $58: 235-259$

53. Wang Y, Dimitrakopoulos P (2006) Nature of the hemodynamic forces exerted on vascular endothelial cells or leukocytes adhering to the surface of blood vessels. Phys. Fluids 18:087107

54. Wankhede SP, Du Z, Berg JM, Vaughn MW, Dallas T, Cheng KH, Gollahon L (2006) Cell detachment model for an antibody-based microfluidic cencer screening system. Biotechnol. Prog. 22:1426-1433

55. White FM (2003) Fluid mechanics. New York : McGraw-Hill

56. Young EWK, Wheeler AR, Simmons CA (2007) Matrix-dependant adhesion of vascular endothelial cells in microfluidic channels. Lab Chip 7:1759-1766 